\title{
ELS INCUNABLES DE FRANCESC EIXIMENIS I ALTRES EDICIONS AL MUSEU I BIBLIOTECA ROSENBACH DE FILADÈLFIA ${ }^{\mathrm{I}}$
}

\author{
GEMMA AVENOZA I LOURDES SORIANO
}

\section{ABSTRACT}

Lecture at the Rosenbach Museum and Library in Philadelphia of the incunabula collection of Dr. A. S. W. Rosenbach, paying special attention to the printed editions of medieval Catalan works by his homonymous the printer Joan Rosenbach of Heidelberg.

\section{INTRODUCCIÓ}

La bibliofília europea i americana de finals del segle xix i primera meitat del segle xx és selectiva, de manera que cada colleccionista s'inclina per un tipus d'obres o per unes altres. Així, quan s'estudia aquesta mena de colleccions privades, hom té la impressió de tenir accés a una part de l'esperit crític o esperit selectiu del seu compilador.

És una sensació molt semblant a la que avui dia es té quan un entra a un museu com el MOMA de Nova York, on les sales no estan organitzades per pintors (és a dir, no tenim fonamentalment una sala dedicada a Pablo R. Picasso o una sala de Paul Gauguin, o una sala dedicada a qualsevol altre pintor), sinó que el que tenim són diverses sales organitzades cronològicament i en les quals s'exposen les colleccions privades; és molt sorprenent i molt impactant poder veure quin era el gust d'un determinat possessor i les obres que va aplegar, allò que ell tenia a casa seva, les obres que realment l'acompanyaven, i més quan una d'aquestes colleccions, la d'Alfred $\mathrm{H}$. Barr, un dels fundadors del MOMA, pot tenir com a peça central Les senyoretes d'Avinyó. És a dir, aquesta visió de la collecció pictòrica privada és molt semblant a la de les biblioteques particulars formades pels bibliòfils de finals del segle xIx i primera meitat del xx. És com una foto fixa del gust i la tria estètica d'un moment determinat, $i$, com que eren totes peces absolutament magnífiques, no importa tant veure la producció d'un pintor concret com contemplar aquella tria que en un moment precís havia donat una determinada sensibilitat.

${ }^{1}$ Aquesta investigació s'ha desenvolupat dins del projecte BITECA (FFI2008-03882), cofinançat amb fons FEDER. Per a les edicions de Joan Rosenbach i els estudis dedicats a les obres que esmentem al llarg del present treball, remetem a les dades que hom pot trobar a PHILOBIBLON. Agraïm a la doctora Elizabeth Fuller, bibliotecària de la Rosenbach Library, la gentilesa amb què ens acollí a la biblioteca i la professionalitat que mostrà al llarg de la nostra estada en posar a la nostra disposició tots els materials que conserven de J. Rosenbach. 
Les colleccions de bibliòfils com Abraham S. W. Rosenbach i altres colleccionistes americans ens porten cap aquí: a una selecció moguda per un interès personal. En posarem uns quants exemples.

Miquel Mateu Pla, financer, empresari i polític català, reuní al castell de Peralada la collecció cervantina més espectacular, una de les millors colleccions privades del món, amb uns cinc mil exemplars, dels quals més de mil són edicions diferents del Quixot.

Archer M. Huntington, fundador de la Hispanic Society of America, mogut pels seus estudis d’hispanística, també aplegà una collecció magnífica de manuscrits i impresos antics; el fil, en aquest cas és més genèric, ja que li interessà la cultura espanyola en general.

O el doctor Rosenbach, el nostre amfitrió. Les seves colleccions més importants són les de judaica i llibres infantils, tot i que un dels motors del seu colleccionisme també va ser la literatura hispànica, en especial la d'un autor com Cervantes, un interès que se li despertà durant la seva època universitària, culminada amb la tesi The influence of Spanish literature in the Elisabethan and Stuart drama (Wolf \& Fleming 39). O la seva collecció d'incunables i postincunables, interès suscitat per un possible lligam familiar.

Per posar un darrer exemple, esmentem el cas de James Ford Bell, home de negocis i filantrop, un colleccionista interessat per la història i l'impacte del comerç internacional anterior a l'any i 800 .

Són, en general, colleccions molt focalitzades i molt diferents de les que es farien des d'una institució pública o no tan marcada per la personalitat del seu fundador.

Totes les colleccions de llibres que s'han format durant les últimes dues centúries depenen, i molt, dels exemplars que estaven a l'abast en el mercat en aquell moment. No seria possible haver reunit, per exemple, una collecció de manuscrits visigòtics perquè no n'hi havia cap a la venda. En canvi, els impresos del segle xvI i aquells sortits de la premsa incunable van estar molt presents en les vendes de llibres des de la finalització de la Revolució Francesa fins a mitjan segle xx, moment en què es dóna una davallada: es troben menys peces importants a la venda $\mathrm{i}$ les poques que encara circulen tenen uns preus absolutament desorbitats.

Per què hi ha aquesta oferta? Per una banda, ens hem de remuntar a la primera meitat del segle xIX i hem de parlar dels efectes de les desamortitzacions, que buiden les biblioteques conventuals i monàstiques i els seus fons bibliogràfics passen a mans laiques; tot $\mathrm{i}$ que hi ha un interès per part de les autoritats civils (ajuntaments, després diputacions) a crear biblioteques públiques (les anomenades Bibliotecas Públicas y Provinciales del Estado), mentre que es decideix qui esdevindrà responsable dels materials, manuscrits i edicions que resten amuntegats i sense protecció en convents exclaustrats i buits. Molts desapareixen llavors, en especial impresos, perquè hi ha poca cura, i sobretot quan es tracta d'exemplars que estan duplicats.

Parallelament, es posen a la venda algunes colleccions i biblioteques angleses molt importants: la biblioteca de Salvá, establert a Londres (comprada per 
Ricardo Heredia i subhastada a París entre els anys i 89 i i 894, molts llibres de la qual acabaran novament al mercat londinenc); la de Richard Heber (venuda en setze vendes repartides entre París, Londres i Gant entre el i 834 i el I 839), o la d'Alfred i Henry Huth (venuda el I9I2 per Sotheby's, els mateixos que subhastaren la biblioteca Beckford l'any I 882) (Avenoza i Soriano).

És a dir, no solament tenim una oferta a l'engròs amb les despulles de la desamortització, sinó que també tenim una oferta selectiva de llibres molt específics, autèntiques joies procedents d'aquestes colleccions en mans privades. Podem afirmar que al segle XIX el llibre antic adquireix valor, importància comercial i raresa bibliogràfica.

Hi ha un mercat i hi ha una oferta, però també han d'existir uns jutges, algú que posi preu, algú que decideixi què mereix la pena comprar i què no. Els compradors, com dèiem abans, molt sovint es mouen per un interès personal, científic, literari, etc., però altres vegades el seu interès també és fer una inversió $i$, per tant, les compres es prioritzaran segons el valor que es doni a determinats llibres. Però, prèviament, algú haurà decidit per què una peça impresa, per exemple, el i 530 pot ser més interessant que una altra que ha vist la llum el I 5 IO. Existeixen uns criteris que guien els colleccionistes i que tenen els seus orígens en unes opinions consensuades. Aquestes directrius s'iniciarien, potser, amb el Manuel du libraire et de l'amateur du livres de Jacques-Charles Brunet, publicat el I 8 Io i revisat i augmentat durant anys successius, que va esdevenir ràpidament el repertori bibliogràfic estàndard.

A partir del I 872, s'hi sumarà el catàleg del bibliòfil i llibreter Pedro Salvá y Mallén, considerat una mena de prèdica del que s'ha de comprar i del que no, $i$ on s'ofereix un decàleg que indica quan un llibre és preuat $i$ imprescindible per engrossir la collecció més exigent.

Un altre criteri per considerar si un llibre era valuós i valia la pena licitar-hi a les subhastes era que hagués format part de la millor biblioteca del seu temps, com, per exemple, la de Richard Heber (Avenoza i Soriano).

Tenim, per tant, qui posa els criteris de qualitat, i després hem de parlar dels compradors. Quant a aquests, el mercat se'l reparteixen bàsicament compradors europeus i americans. Entre els primers, els anglesos són els més actius. Les seves biblioteques, a la llarga, també es posaran a la venda i finalment acabaran o a la British Library, disperses per biblioteques europees o, en la majoria dels casos, comprades en bloc per bibliòfils americans. Davant de la pèrdua d'autèntiques joies, els bibliòfils anglesos es lamentaven i el doctor Rosenbach els assegurava que no era una pèrdua real per al món erudit; quan li ho preguntaven, sempre contestava amb una altra pregunta: ¿on era un llibre rar més accessible, a la biblioteca privada d'un noble anglès, tancada i a la qual un investigador no té accés, o a la d'un gran colleccionista americà, la qual, al cap i a la fi, acabaria oberta al públic o llegada a una universitat? ("Chief Book Gems»).

Alguns bibliòfils americans compren directament a les subhastes europees, tot i que molts no van fer l'adquisició per ells mateixos, sinó que la van fer a través d'intermediaris, de llibreters, com ara mateix algunes de les grans com- 
pres fetes a Sotheby's. Portarem a collació el còdex de mitjan segle xv amb el Compendi historial de Jaume Domènech. El manuscrit, que havia estat de la biblioteca del Convent de Carmelites Descalces de Barcelona i es creia perdut, fou subhastat per la casa anglesa el I99 i venut al llibreter H. P. Kraus per a un colleccionista barceloní.

La raó és ben senzilla: els llibreters coneixen millor el mercat, poden trobar millors preus i, a més a més, d'aquesta manera també s'amaga la identitat del comprador i la destinació final del llibre. És, per exemple, el cas del manuscrit del segle xv que conserva l'única còpia del Llibre de cetreria escrit per Antoni de Vilaragut i que posseïa l'industrial i bibliòfil francès Marcel Jeanson. El manuscrit en qüestió aparegué a la subhasta de la casa Claude Agutte a París el 2003 amb un preu de sortida de $15.000-20.000$ euros i fou adquirit per uns 35.000 euros per un personatge anònim, alhora que es tirava la cortina de fum que havia estat comprat per un colleccionista privat del Pròxim Orient. Per tant, ni era estranya abans ni és estranya ara la intervenció de llibreters intermediaris.

Alguns d'aquests llibreters es movien per diverses places europees i compraven, sobretot, a Londres, París i alguns, pocs, també a Madrid. Londres va ser la ciutat on el doctor Rosenbach va fer la majoria de les seves adquisicions, com a llibreter comprant per als seus clients i per a ell en tant que bibliòfil interessat en les seves pròpies colleccions. No és un cas estrany entre els llibreters - recordem, per exemple, Salvá o Vindel, també grans llibreters i bibliòfils-. Algunes de les colleccions més importants de llibres rars dels Estats Units foren formades amb l'ajuda del doctor Rosenbach. Per exemple, la de Henry Huntington a San Marino, Califòrnia; o la de Harry Elkins Widener a Harvard, aquest darrer mort tràgicament durant la travessia del Titànic i de qui el doctor Rosenbach opinava que si hagués sobreviscut hauria estat el més gran bibliòfil de la història (Basbanes I 86-I87).

Abraham Rosenbach comprava per vendre, però, a diferència d'altres llibreters, aquestes vendes li havien de reportar publicitat i amb ella prestigi. No és gratuiit, en el seu cas, el sobrenom pel qual era conegut entre bibliòfils i llibreters, el «Napoleó dels llibres», perquè quan arribava a una subhasta s'enduia les millors peces i era temut per les seves licitacions, ja que feia pujar els preus fins a cotes inassequibles per als altres compradors, cosa que arribava a provocar l'exasperació dels seus collegues, però que, al cap i a la fi, li garantia l'adjudicació de la peça (Trakosch 25-28; Wolf I 3 -I4).

D'altra banda, tampoc no ens ha d'estranyar aquesta manera de procedir, perquè també Vindel, per exemple, pujava molt els preus dels llibres, cosa que irritava molt Menéndez Pelayo, en part perquè tenia compradors tan acabalats com Huntington o Lázaro Galdiano.

La compravenda que més bé illustra el caràcter del doctor Rosenbach és la del manuscrit d'Alícia al país de les meravelles de Lewis Carroll (Basbanes 2 102 I I). Contactat primerament per a la seva compra per la bibliotecària de J. P. Morgan, Belle da Costa Green, Rosenbach l'adquirí en subhasta per i 5.400 lliures l'abril del I928 i es va oferir a vendre'l de nou a la Gran Bretanya pel que 
ell havia pagat. El negoci no prosperà i va portar el manuscrit als Estats Units, on el va exhibir àmpliament en biblioteques de Filadèlfia, Boston, Washington i Nova York. Després el va vendre al colleccionista Eldridge R. Johnson i, quan aquest va morir, Rosenbach el va adquirir de nou per 50.000 dòlars, va organitzar una campanya per recaptar fons i el va retornar al Museu Britànic en nom del poble americà. Es a dir, no solament va restituir aquest tresor bibliogràfic a Anglaterra després de posseir-lo per un temps, sinó que va ser capaç d'obtenir gràcies a ell el màxim de publicitat $\mathrm{i}$ beneficis.

La formació de les colleccions privades del doctor Rosenbach depèn de diversos factors. No es queda amb allò que no ha pogut vendre després. Selecciona peces que reserva per a ell mateix.

És interessant conèixer quin és el criteri que cada bibliòfil té a l'hora de formar la seva biblioteca. La biblioteca de Richard Heber, per exemple, és paradigmàtica d'una bona collecció, formada per algú que té una idea molt clara de què entra a la seva biblioteca i què no. Considerava, per exemple, que durant l'època incunable i postincunable es van imprimir moltíssims llibres de temàtica religiosa en llatí, per la qual cosa no els considerava importants: no eren precisament prioritaris dins de les seves colleccions, i fins i tot, eren llibres bandejats.

En el cas del doctor Rosenbach, són prou conegudes les seves colleccions més importants, com ara la de literatura anglesa de les Illes Britàniques, o les de Judaica, llibres infantils o d'Americana (és a dir, obres sobre la descoberta d'Amèrica $\mathrm{i}$ la història militar des dels primers establiments fins a la Guerra Civil), en aquests tres casos continuant la tasca del seu oncle Moses Polock, també llibreter i qui l'inicià en el negoci familiar. També són prou importants les peces de literatura espanyola amb Cervantes al capdavant.

Donada l'amplitud del interessos del doctor Rosenbach, tindríem alhora un criteri condicionat per l'oferta del lloc on ell estava i, després, que trobés una peça que li interessés. Això fa que tot allò que es va moure a través del mercat de París estigui fora de la seva collecció perquè tenia la seva activitat centrada en un altre lloc.

Allò que ens ha portat a la biblioteca Rosenbach avui com a catalanistes és el nostre gust pel llibre antic i medieval. Aquesta és una collecció que aplega magnífics exemplars incunables i postincunables de Joan Rosenbach, un dels impressors més importants de l'àrea catalana i preuat sobretot com a impressor d'obres litúrgiques.

\section{Johannes Rosenbach I LA SEVA PRODUCCió}

Joan Rosenbach (floruit I490-I530) es dedicà a la impremta durant gairebé quaranta anys. Desenvolupa el seu ofici en diversos indrets, encara que en alguns casos les dades de la seva activitat són de caire documental i no se n'han conservat impressions: València (I 490-I 49I), Barcelona (on imprimeix catorze obres durant els anys I492-I498), Tarragona (des del I498 fins al febrer del 
I 500), Perpinyà ( I 500-I 503), amb un buit d'informació per als anys i 504-i 505, reapareix a Barcelona el I 506 on publicarà fins al I 520 i, finalment, Montserrat (I I I 8-I 520 - març del I 522). La darrera obra que sortirà de la seva premsa és l'Ordinarium Tarraconense, amb colofó del 7 de febrer de I 530.

La producció del seu taller és molt àmplia i variada: sembla que fins i tot a l'etapa de Barcelona durant el segle xvi se li adjudiquen unes cinquanta edicions (Norton en cataloga quaranta-vuit i Martín Abad cinquanta), i això només en una de les ciutats on va treballar, que és moltíssim, i és una obra molt àmplia. Però, si comparem el fons en llengua romànica que hem detectat als Estats Units amb el conjunt de la seva impressió, no totes les edicions es poden trobar aquí (Avenoza i Soriano). En el cas de les compres fetes pel doctor Rosenbach, la seva collecció està molt condicionada pels llibres que realment estaven a la venda en el moment en què ell va formar la seva collecció. Se li poden escapar de manera voluntària els llibres de matèria litúrgica i en llatí, i també aquells que no es van posar mai a la venda en el seu període d'activitat, especialment aquells llibres conservats en exemplar únic.

Això no vol dir que la seva collecció no estigui plena de joies. Té exemplars que són realment rars, com per exemple la Biblia parva. El seu exemplar és molt important perquè només se'n conserven dos més, i, a més a més, és una edició amb molta polèmica perquè va patir una falsificació parcial al segle XvII (Riera).

\section{Rosenbach A BARCELONA}

Rosenbach va imprimir almenys trenta-set edicions d'obres en català, segons consta a les dades de BITECA, tot i que dues d'aquestes impressions no s'han conservat (i hi ha dubtes sobre la seva existència, vegeu infra).

El llibreter i bibliòfil Abraham S. W. Rosenbach adquirí sis exemplars d'aquestes edicions $i$ ens hem preguntat per què no en va comprar més, quan era clar el seu interès pels llibres sorgits de les premses del llibreter de Heidelberg i, en termes de valor dels llibres, els textos en «llengua lemosina» eren dels més apreciats, sobretot a partir del decàleg del bibliòfil posat en circulació per Salvá. ${ }^{2}$

De les trenta-set edicions esmentades, hem examinat amb detall els casos d'un únic exemplar conservat i els dels llibres que va comprar el doctor A. S. W. Rosenbach, per tal d'entendre les raons per les quals uns volums arribaren a les seves mans i d'altres no. Atès que el prestigi marcava també el preu, hem dividit l'anàlisi entre els exemplars incunables i els del segle xvI (sense fer, entre aquests, distinció entre postincunables $\mathrm{i}$ edicions posteriors al $\mathrm{I} 520$, per qüestions pràctiques). ${ }^{3}$

${ }^{2}$ «En todas estas clases, también respectivamente, gozan de mayor aprecio bibliográfico los libros en lemosín y vascuence, ó los escritos en algunos de los dialectos de América» (Salvá y Mallén XIV).

${ }_{3}^{3}$ Martín Abad defineix com a postincunables «los ejemplares de ediciones impresas en talleres de España y Portugal entre los años I 50 I y i 5 20» (Post-incunables I: I 5 ). 
Onze són les edicions incunables fetes per Joan Rosenbach a Barcelona, entre el 3 de novembre de I 492 i el 28 de març de I 498 , cinc de les quals es troben al The Rosenbach Museum and Library.

\section{Relació DE LES EDICIONS INCUNABLES DE ROSENBACH FETES A BARCELONA}

\begin{tabular}{|c|c|c|c|c|}
\hline I 788 & 3 & Barcelona & Joan Rosenbach & I $492-10-03$ \\
\hline 1830 & I & Barcelona & Joan Rosenbach & I $493-09-$ I 8 \\
\hline 1902 & 2 & Barcelona & Joan Rosenbach & I 494-O2-O I \\
\hline 1558 & 9 & Barcelona & Joan Rosenbach & I $494-02-\mathrm{I} 4$ \\
\hline I 559 & 5 & Barcelona & Joan Rosenbach & I $494-05-30$ \\
\hline I 487 & IO & Barcelona & Joan Rosenbach & I $494-06-2$ I \\
\hline I739 & I I & Barcelona & Joan Rosenbach & c. 1495 \\
\hline I $47 \mathrm{I}$ & 19 & Barcelona & Joan Rosenbach per a J. Bernat & I $495-05-08$ \\
\hline I 868 & 8 & Barcelona & Joan Rosenbach & I $495-06-04$ \\
\hline I 386 & I & Barcelona & Joan Rosenbach & I 495 -I I-27 \\
\hline I56I & 2 & Barcelona & Joan Rosenbach & I $498-03-28$ \\
\hline
\end{tabular}

Podríem dir que els exemplars més preuats avui dia són els que conserva la British Library, car són exemplars únics: Diego de San Pedro, Càrcer d'amor (I 8-9-I 493) i Antoni Boteler, Scala de paradís (27-I I-I 495). Cap no va estar a l'abast de Rosenbach, car van sortir al mercat al segle xIx, anys abans que comencés la seva apassionada caça dels exemplars de bibliofília en fer-se càrrec del negoci familiar el I903. L'exemplar de la Càrcer d'amor (London BL IA.52542) procedeix de la collecció de Thomas Grenville, donada a la seva mort a la Biblioteca, el I 846. No tenim una informació tan concreta sobre el moment en què la Scala de paradís (London BL IA. 52546 ) ingressà a la biblioteca britànica, però el llibre va pertànyer a Salvá i més tard a Heredia, la biblioteca del qual es vengué a París als voltants dels anys i 89i-i 894 (Catalogue).

En totes les professions hi ha rivalitats, i, en el cas dels llibreters, els Qua-

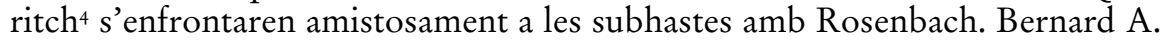
Quaritch (fill) i després la firma Quaritch dirigida per la germana gran competien sovint amb Rosenbach per les mateixes peces, com, per exemple, a la venda Britwell del I 922 en què Rosenbach pagà 63.000 lliures de les 83.000 recaptades, però no sempre fou ell qui aconseguí quedar-se els fons (Basbanes 202-

${ }_{4}$ Bernard Quaritch pare I819-I 899 i Bernard A. Quaritch fill I 869-I9I 3, succeit al negoci per les seves germanes, que convertiren la firma en una companyia limitada amb seu a Londres dedicada a la compra de llibres. Tota la informació d'aquesta presentació procedeix de l'examen dels catàlegs de vendes Quaritch conservats a la biblioteca del Grolier Club (NY). 
203). Els Quaritch, des de molt abans que Rosenbach entrés al mercat del llibre, tenien entre els seus clients la British Library, per a la qual potser van adquirir part de la venda Heredia i, per tant, la Scala de paradís.

Rosenbach no aconseguí quatre altres edicions incunables, bé perquè no eren al mercat (Llegenda aurea), perquè tal vegada no li interessaven (Sentència dels remenses) o perquè les adquirí per a algun dels seus clients:

- La Legenda aurea de J. de Varazze (MANID i902) de l'i de febrer de I 494 (dos exemplars: un a Madrid, BNE I-2000, que fou de Jerónimo Martínez de la Vega, i un altre a Barcelona, BUB I-2000, procedent del Convent del Carme Descalç);

- Les Constitucions de 30-5-I494 (MANID i 559) del 30 de maig de I494 (cinc exemplars: dos a Barcelona, BC Ms. 754 (I) olim F. de Sagarra, Esp 3 Fol olim Espona; un altre a Londres, BL IB 52544 olim Olschki; un a Vic, Capitular I-92, i un altre a BNF Rés F. 682 olim Biblioteca Reial);

- Felip de Malla, Memorial del pecador remut c. I495 (MANID I739) de c. I 495 (dotze exemplars conservats: dos a Barcelona, BC Esp. 6 Fol olim Espona, I I-VII-I olim Aguiló, i altres exemplars a Sevilla, Colombina I 2-5-23; València, Serrano Morales olim Serrano Morales; San Marino Huntington 84486 olim Salvá i Heredia; Montserrat Monestir S.I.4-107; BNF Rés D.34I4 olim biblioteca reial; Madrid BNE I-2330; Rouen Municipale Mt T 240 olim Barcelona Biblioteca Mariana de S. Francesc; Mallorca, Pública Sig. Bib. Inc. 477 olim Convent del Carme i BL IB. 52548). Rosenbach tenia entre els seus clients H. E. Huntington, per a qui segurament devia comprar el llibre.

- Ferran II, Interpretació sobre la sentència dels remenses (MANID i $56 \mathrm{I}$ ) del 28 de març de I 498 (dos exemplars conservats: un a Barcelona, ACA Inc-50 olim Cancelleria Reial, i un altre a la BC F.B.2362 olim Bonsoms).

Avui a la Rosenbach Library trobem els cinc incunables que Rosenbach aconseguí comprar:

I. MANID i788. Llibre del bisbe de Jaén (3-IO-I492). Es conserven tres exemplars d'aquesta rara edició: el de la Rosenbach Library I-492p (olim un canonge de València, Josep Sanchis al segle xviI, Madrid, Archivo de la Junta de la Concepción i 860 en època posterior a la desamortització, Baldiri Carreras i finalment London Maggs Bros, que fou qui el vengué a Rosenbach); el de Madrid, BNE I-950 (procedència desconeguda), i el de BL IA. 52540 (olim el batxiller Joseph Coy, sense que es conegui on ni com l'adquirí la BL). Només l'exemplar comprat pel doctor Rosenbach sortí al mercat aquells anys.

2. MANID I 558. Constitucions de Catalunya (I4-2-I 494). Se'n conserven nou exemplars: tres a Barcelona, BC 9-VII-30 (olim Aguiló); Barcelona, Arxiu Històric Res $4^{\circ}$ op. 2 (procedència desconeguda) i Advocats Sign 316 (olim Guillem M. de Brocà), un a Vic, Capitular I-9I (procedència desconeguda), i un altre a El Escorial, Biblioteca del Monestir d.II.r 2 (2) (olim Bisbe Antoni Agustí Albanell). Els cinc restants són fora d'Espanya: tres a Europa: París, Sainte Geneviève OE XV 648 Rés (pièce 4) (olim Joan Jovells; París, Abbaye de Ste. Geneviève, Colbert); Cambridge Univ. SSS.40.17 (olim Samuel Sandars, ingres- 
sat a la Biblioteca abans del I 894) i Milà, Ambrosiana, S.N.V.X.20 (procedència desconeguda); l'últim és a la Rosenbach Library I-494c (olim Pedro Vila, Mossèn Jaume Pou). La major part d'aquests exemplars eren a les biblioteques des d'època bastant antiga. Només podem parlar de dos que hagin sortit a la venda en temps moderns: el d'Aguiló, del qual desconeixem la procedència, i el que es comprà per a Cambridge a costa de Sandars (a. I894) i, per tant, anterior a l'activitat de Rosenbach i que és el que adquirí el doctor Rosenbach.

3. MANID 1487. Francesc Eiximenis, Llibre dels àngels (2 I-6-I494). Se'n conserven deu exemplars. Vuit a Espanya: Barcelona, BC Bon7-IV-28 (olim Joannes Rocanus, Gabriel Alzines prevere de Vic i Jaume Espona); Barcelona, BC Esp 9 Fol (olim Joan Libra); Barcelona, BU I-486 (procedència sense confirmar); Barcelona, Seminari I-47 (olim Barcelona Arxiu Episcopal); València, BHUniv. I-47 (olim València, Convent de Montesa); Mallorca, Bib. Municipal (exemplar no trobat); Montserrat, Monestir $4^{\circ}$ - 102 (olim antiga biblioteca del Monestir), i Madrid BNE I-2086 (procedència desconeguda). Només dos exemplars van creuar les fronteres: París, BNF Rés D. 300 (Colbert, Biblioteca reial) i Rosenbach Lib. I-494x (olim Barcelona, Biblioteca Mariana de San Francesc). En aquest cas, Rosenbach va fer-se amb l'únic exemplar posat a la venda d'aquesta edició en el seu temps. L'obra es trobava a la major part de les biblioteques monàstiques, si no a totes, $\mathrm{i}$ amb la desamortització una bona part dels exemplars que eren als convents van passar al mercat del llibre antic, com és el cas dels actuals BC Bonsons i BC Espona, segurament també el de la BNE, i el que va adquirir el doctor Rosenbach, que segurament havia estat abans en mans d'algun bibliòfil, tal vegada anglès. Almenys un d'aquests exemplars procedeix de la Biblioteca Salvá, tot i que encara no l'hem identificat. Altres exemplars procedents de convents passaren a arxius eclesiàstics (el del Seminari, el de Montserrat, que potser mai no va canviar de seu) i d'altres s'integraren en les biblioteques públiques que recolliren els fons supervivents (el de la Pública de València).

4. MANID I47I. Francesc Eiximenis, Llibre de les dones (8-5-I495). Se'n conserven divuit exemplars, dels quals romangueren a Espanya els següents: Barcelona, BC ıo-VI-34, BC I I-VII-5; Barcelona, ACA I-32; Ripoll, L. Mata R ıо5; Vilanova i la Geltrú, M. Balaguer; Madrid, BNE I-624; Madrid, BNE I-20I9; Vic, Capitular I-ı09. A Europa n'hi ha cinc exemplars: Chantilly, Inst. France IVh/I 4 (olim Josep Miró, canonge de Vic, i R. Heredia); Marsella, L'Alcazar I-65 (no se'n coneix la procedència); Perpinyà, Médiathèque I-78 (no se'n coneix la procedència); Berlín, Preussische St. Inc. 4962/20 (Biblioteca Regia), i París, BNF Rés D.294I (Saragossa, Agustins Descalços). Cinc altres exemplars es troben a biblioteques anglosaxones $i$ hi van ingressar com a resultat de vendes fetes en el temps en què Rosenbach era actiu: Cambridge (MA), Harvard Houghton I-95 5 I (30 olim Barcelona, Biblioteca Mariana de S. Francesc i A. C. White); Burlington, Bailey, NY HS. Inc. (no se'n coneix la procedència); Philadelphia Rosenbach Lib. I-495x (olim Matías Erráruriz), i San Marino, Huntington 8448 I (olim Pedro de Rayana, no en coneixem el venedor). La coincidència simultània en el mercat d'exemplars d'un mateix incunable es pot explicar per les transaccions de 
llibres que tingueren lloc després de la desamortització dels béns eclesiàstics, com apuntàvem amb referència al llibre anterior, però en aquest cas ens trobem amb una situació sorprenent, car en un mateix moment estan a la venda no menys de cinc exemplars de l'obra, que són, a més, exemplars en molt bon estat. Hi podríem afegir també els del fons Aguiló de la BC, els de la Lambert Mata de Ripoll i del Museu Balaguer de Vilanova i la Geltrú, fons tots ells construïts a partir de llegats de bibliòfils de la primera meitat del segle xx (i també podrien procedir del mercat del llibre el de la BNE i el de Perpinyà). Això ens duria a trobar a la venda entre el I 870 i el I 940 onze exemplars de l'edició, és a dir, més de la meitat dels testimonis supervivents, un dels quals era a

5. MANID I 868. Pere Tomich, Històries $i$ conquestes (4-6-1495). Està representat actualment per vuit exemplars. A Espanya se'n documenten sis còpies: Barcelona, BC 764 (2) (olim Ferran de Sagarra); Madrid, BNE I-r98 I (procedència desconeguda); Madrid, RAH I-6I (olim Joachimi Varen); Alacant, Bosc d'Arés (biblioteca privada no estudiada), i un exemplar que era a Ripoll, a la Biblioteca Lambert Mata, i que avui no ha estat possible trobar. Els altres tres exemplars es conserven a Amèrica: un a la Rosenbach Library I-495t (J. Ripoll canonge de Vic, Mariano Sadurní i en temps moderns Barcelona, IEC); un altre a NY HS (olim W. H. Crawford, veg. Basbanes I 4I), i un altre a San Marino, Huntington 84480 (olim Hiersemann). Els testimonis americans procedeixen de vendes fetes a les primeres dècades del segle xx o les darreres del XIX, quan almenys tres exemplars de l'obra foren oferts pels llibreters. Quaritch en posà a la venda dos exemplars el i 885 i, de nou, el I886-i888. No tenim notícia de l'aparició al mercat del tercer exemplar.

El doctor Rosenbach preferia els incunables, com tot bon bibliòfil, però no va deixar escapar voluntàriament cap peça postincunable accessible. Així és com trobem entre els seus llibres els Privilegis de la vila de Perpinyà, imprès a Barcelona el 29-4- I 5 Io (BITECA MANID 2652). D'aquesta obra se'n conservaven cap al 1960 nou exemplars, dels quals només dos són a Espanya: Barcelona, BC 6-VII-2 I (olim Mossèn Joan Antoni Ferrer i Josep Bertran), i Barcelona, ACA (exemplar que encara no hem examinat). Sis són a Europa: tres a Perpinyà: Médiathèque Rés 434 (olim Antoni Blanquet), Miquel Paredes-Donolla (biblioteca privada a la qual no hem accedit) i Archives Municipales AA.7 (procedència desconeguda); un a Berlín, Preussische St. Ht 6i I I (Antoni Tallarch); un altre a París, BNF Rés LK 7-7869 (olim París, Companyia de Jesús); un altre a Londres, BL C.63.i.9 (procedència desconeguda), i el darrer el trobem a Filadèlfia, Rosenbach Library $\mathrm{C}_{2} \mathrm{Alr}$ (olim Honorat Pou).

Segurament també li hauria interessat fer-se amb els exemplars únics de les tirades de J. Rosenbach, però hem pogut comprovar que en els casos en què aquests van sortir al mercat bibliòfil, va adquirir les peces un altre dels seus competidors, Hiersemann, que comprava per a A. Huntington. Aquest és el cas, per exemple, de G. Cauliach, Cirurgia I-4-I 508, avui a NY HS Reserve Medicina $\mathrm{HC}_{327 / 1} 350$, olim Hiersemann; La verge Maria del Puix de França I 5 10 [?], també a NY HS Reserve *Religion (double oversized) [sic, signatures 
en curs de revisió per la biblioteca] Mary, mother of Christ. La verge Marie del Puix... [Barcelona?] I 508, olim Hiersemann, i Contemplació sobre la pasió 5-2I 5 I 3 , ara a NY HS Religion, sense signatura, olim R. S. Turner, sense que ens consti si fou Hiersemann qui proporcionà el llibre a A. Huntington.

Si deixem de banda els dos exemplars de la collecció Aguiló:

- B. Granollachs, Llunari (I0-3-I I I3) ara a Barcelona BC i I-VI-I I, olim Aguiló;

- M. Comalada / [anònim?], Spill de la vida religiosa (20-10-I I I ) ara a Barcelona BC i I-V-i s, olim Aguiló,

i les dues edicions del Llunari de B. Granollachs (I4 I9 i ro-I 2-I I I 4 olim Reus, Font de Rubinat), de les quals no tenim notícia de cap exemplar conservat, totes les altres peces havien sortit del mercat molts anys abans $\mathrm{i}$ es troben a les colleccions d'Hernando Colón:

- Esteve Rotllan, Judici e pronostic is I3-I I Is?, Sevilla, Colombina I 2- II 8 (I9);

- G. Nicolau, Forma donada als confrares... c. is is, Sevilla, Colombina I 4-2-7 (8)

- M. Ortigues, Obres i 528, Sevilla, Colombina, 4-3-44 (I).

De la Biblioteca Universitària de València:

Miquel Ortigues, Obres poètiques (I I I 2?). València, BHUniv. Bh CF/4 8.

\section{RELACIÓ DE LES EDICIONS DE ROSENBACH}

A BARCELONA AL SEGLE XVI

\begin{tabular}{|c|c|c|c|c|}
\hline 2670 & 2 & Barcelona & Joan Rosenbach & I $507-03-20$ \\
\hline 2602 & I & Barcelona & Joan Rosenbach et al. & I 5O8-O4-OI \\
\hline 2706 & 2 & Barcelona & Joan Rosenbach & I $509-05-20$ \\
\hline $265 \mathrm{I}$ & I & Barcelona & Joan Rosenbach & I $510[?]$ \\
\hline 2652 & 9 & Barcelona & Joan Rosenbach & I $510-04-29$ \\
\hline 704 & 4 & Barcelona & Joan Rosenbach & ISII \\
\hline $252 \mathrm{I}$ & I I & Barcelona & Joan Rosenbach & I 5 I 2-[?] \\
\hline 2688 & I & Barcelona & Joan Rosenbach & I 5 I 2-[?] \\
\hline 2425 & I & Barcelona & Joan Rosenbach & $\begin{array}{l}\text { Is I } 2 \text { a quo- } \\
\text { I5 I3-o8 ad } \\
\text { quem }\end{array}$ \\
\hline 2650 & 7 & Barcelona & Joan Rosenbach & c. $15 \mathrm{I} 2$ \\
\hline 2654 & 2 & Barcelona & Joan Rosenbach per a B. Aguilar & I 5 I3-[?] \\
\hline 2649 & I & Barcelona & Joan Rosenbach & I $513-02-05$ \\
\hline 2308 & I & Barcelona & Joan Rosenbach & $1513-03-10$ \\
\hline 2447 & 6 & Barcelona & Joan Rosenbach & $1513-05-12$ \\
\hline
\end{tabular}




\begin{tabular}{|c|c|c|c|c|}
\hline 1067 & I & Barcelona & Joan Rosenbach & I 5 I 4-I 2-IO \\
\hline 2349 & I & Barcelona & Joan Rosenbach & c. Is Is-[?] \\
\hline 2229 & 7 & Barcelona & Joan Rosenbach & ISIS-O2-IS \\
\hline 2644 & I & Barcelona & Joan Rosenbach & I S I S-IO-20 \\
\hline 2494 & 6 & Barcelona & Joan Rosenbach per a J. Trinxer & I 5 I 8 -IO-I 6 \\
\hline 2430 & IO & Barcelona & Joan Rosenbach per a R. Dauder & I 5 I $8-05-06$ \\
\hline I997 & 5 & Barcelona & Joan Rosenbach & I $519-02-20$ \\
\hline I 764 & I & Barcelona & Joan Rosenbach & I5 I9 \\
\hline 22 I I & I 3 & Barcelona & Joan Rosenbach & I $520 \mathrm{~d}$. \\
\hline 2655 & 6 & Barcelona & Joan Rosenbach & I $522-02-08$ \\
\hline 2207 & I & Barcelona & Joan Rosenbach & I $228-08-05$ \\
\hline
\end{tabular}

\author{
GEMMA AVENOZA-LOURDES SORIANO \\ IRCVM (Institut de Recerca en Cultures Medievals) - \\ UB (Universitat de Barcelona)
}

\title{
REFERÈNCIES
}

Avenoza, Gemma i Lourdes Soriano. «Sixteenth-century Editions of Medieval Catalan Works in North American Collections.» Papers of the Bibliographical Society of America. En premsa.

Basbanes, Nicholas A. A Gentle Madness. Bibliophiles, Bibliomanes, and the Eternal Passion for Books. Nova York: Henry Holt and Company, I999.

BRUNET, Jacques-Charles. Manuel du libraire et de l'amateur de livres. sa ed. París: Firmin Didot, I 860-1878. 8 v.

Catalogue de la Bibliothèque de M. Ricardo Heredia, comte de Benahavis (Vente an I2 Avril an II Mai I 894. Salles Silvestre). París: Paul et Guillemin, I 89I-I 894. $4 \mathrm{v}$.

«Chief Book Gems Comig to America». The New York Times I I febrer 1922. http://query.nytimes.com/mem/archive-free/pdf?res=Foo9 I IFD $3554 \mathrm{IB} 7$ A93 $\mathrm{C}_{3} \mathrm{~A} 8 \mathrm{I} 789 \mathrm{D} 85 \mathrm{~F}_{4} 68285 \mathrm{~F} 9>$ (data consulta: febrer de 2010 ).

Martín Abad, Julián. Post-incunables ibéricos. Madrid: Ollero y Ramos, $200 \mathrm{I}$. $2 \mathrm{v}$.

Norton, F. J. A descriptive catalogue of printing in Spain and Portugal (I SOII 520). Cambridge: Cambridge UP, I 978.

Riera i SANs, Jaume. «La doble falsificació de la portadella d'un incunable (Hain I 2433)». Revista de Llibreria Antiquària octubre 1985 :5-17.

Rosenbach, A. S. W. Books and Bidders. The Adventures of a Bibliophile. Londres: George Allen \& Unwin Ltd., I928. 
Salvá y Mallén, Pedro. Catálogo de la biblioteca de Salvá. València: Imprenta de Ferrer de Orga, I872. 2 v.

Trakosch, Avery. «Profiles. Napoleon of Books». The New Yorker I 4 abril I928: $25-28$.

Wolf, Edwin i John Fleming. Rosenbach. A Biography. The Life of One of the Greatest Book Collectors. Londres: Weidenfeld and Nicolson, I960. 